\title{
Der Kampf um die Kultur
}

\section{Zur Ent- und Re-Soziologisierung eines ethnologischen Konzepts}

\author{
Von Carola Lentz
}

Zusammenfassung: Sowohl Ethnologie wie Soziologie werden durch die Globalisierung herausgefordert. Die vermeintlich abgeschlossenen fremden „Völker“ verschwinden; „Gesellschaft" nationalstaatlich zu konzipieren, wird immer unplausibler. Eine (Wieder)Annäherung der beiden im neunzehnten Jahrhundert ausdifferenzierten Fächer tut Not. Taugt „Kultur“ dafür als Brückenbegriff? Soziologen wie Andreas Reckwitz werben für eine praxis- oder diskurstheoretische Reformulierung des Kulturkonzepts, tragen dabei aber auch zu einer problematischen, weil zu umfassenden „Kulturalisierung“ des Sozialen bei. Dagegen halten Ethnologen wie Adam Kuper oder Chris Hann den Kulturbegriff für so unrettbar reifiziert, diffus und machtblind, dass sie ihn lieber abschaffen oder doch umfassend „soziologisieren“ und durch eine präzisere Benennung der jeweils gemeinten symbolischen Codes oder sozialen Praktiken ersetzen wollen. Der vorliegende Artikel schließt sich eher den Skeptikern an und zeichnet aus dieser Perspektive die wichtigsten Stationen der „Entsoziologisierung“ des klassischen ethnologischen Kulturbegriffs und die neuere Kritik in der Ethnologie sowie Ansätze nach, Kultur als Arena von machtförmigen Aushandlungsprozessen $\mathrm{zu}$ begreifen.

\section{Einleitung}

Über das „schwierige Verhältnis“ zwischen Ethnologie und Soziologie hat Karl H. Hörning (2008) kürzlich in einem anregenden wissenschaftsbiographischen Aufsatz in einer ethnologischen Fachzeitschrift nachgedacht. In den 1960er Jahren studierte Hörning in Heidelberg, wo Ethnologie und Soziologie unter der Leitung des Ordinarius für Soziologie und Ethnologie Wilhelm Emil Mühlmann für zehn Jahre in einem Institut vereint waren - ähnlich wie einst in Chicago oder auch an der Harvard University im von Talcott Parsons geleiteten Department of Social Relations. Doch blieben solche Kooperationen zwischen Ethnologie und Soziologie Ausnahmen. In Heidelberg wurde das Experiment mit Mühlmanns vorzeitiger Emeritierung im Jahr 1970 beendet und die Ethnologie an das Südasien-Institut verlagert. Neben der Aufdeckung von Mühlmanns nationalsozialistischer Vergangenheit trug dazu vor allem auch ein genereller Trend in der Soziologie bei, die sich in den 1970er und 1980er Jahren auf eine „Binnenschau auf den Umbau der Industriegesellschaft“ beschränkte, wie Hörning zuspitzt. Dafür spielte die Ethnologie keine Rolle, höchstens als Lieferantin von zeitlich und räumlich weit entfernt liegenden Beispielen angeblich ,einfacher" gesellschaftlicher Organisationsformen, die „lediglich als Abstoßfolie für die große Erzählung von der modernen Gesellschaft" dienten (Hörning 2008: 46 f). Die Ende des neunzehnten Jahrhunderts etablierte Arbeitsteilung zwischen der Ethnologie als Wissenschaft der ,anderen“, außereuropäischen, ,vormodernen“ Gesellschaften und der Soziologie als Wissenschaft der westlichen „Moderne“" setzte sich damit fort. Sie wurde noch verstärkt durch methodische Präferenzen - der Ethnologie für Mikrostudien mit qualitativen Methoden und der Mainstream-Soziologie für große Untersuchungseinheiten, ein deduktives Forschungsdesign und standardisierende, quantifizierende Verfahren.

De facto wurden und werden diese Trennlinien vielfältig unterlaufen. Ethnographische Verfahren waren in der amerikanischen Soziologie auch mit dem Ende der ersten Chicagoer Schule nie verschwunden und haben seit Jahren in der deutschen Soziologie zunehmend Fuß gefasst. Die Entwicklungssoziologie arbeitet quer zu den etablierten geographischen ,Zuständigkeiten", und in der Sektion Entwicklungssoziologie und Sozialanthropologie der Deutschen Ge- 
sellschaft für Soziologie, die nicht zufällig von den Heidelberger Absolventen Georg Elwert und Dieter Goetze gegründet wurde, wirken Ethnologen und Soziologen seit Langem zusammen. Doch sind solche Querverbindungen nicht in die Kernzonen der jeweiligen Fachverständnisse vorgedrungen. Dabei hat die Globalisierung beide Fächer verunsichert und legt einen neuen wissenschaftlichen Austausch nahe. Die Ethnologie hat ihre scheinbar abgeschlossenen „Völker“ verloren, deren Mitglieder längst weltweit migrieren und für vielfältige Austauschprozesse sorgen; die Soziologie kann Gesellschaft nicht mehr an nationalstaatlichen Grenzen festmachen und ist mit zunehmend inhomogener werdenden Gebilden konfrontiert. Ulrich Beck kritisiert seit Langem den methodologischen Nationalismus der Soziologie und plädiert für einen „kosmopolitischen Blick“ (2004); an der Universität Bielefeld hat sich ein Institut für Weltgesellschaft gegründet. Dennoch bleibt die Zusammenarbeit mit der Ethnologie zögerlich.

Viel spricht also dafür, erneut über die beiden Fächer Verbindendes nachzudenken. Hörning schlägt dafür das Thema „Modalitäten des Wissens“ vor, bei dem die Soziologie von der methodischen Expertise der Ethnologie profitieren könnte, „,nicht vertextetes [...] kulturelles Handlungswissen“ (2008: 54) zu erforschen. „Kultur“ tauge dagegen nicht als ,allgemeiner Brückenbegriff“, weil er im Zuge des „rasanten Aufstieg[s] der Kulturwissenschaften“ allzu inflationär gebraucht werde (2008: 41). Ich teile Hörnings Skepsis bezüglich des Kulturbegriffs, meine aber, dass eine (Wieder)Annäherung beider Fächer dennoch erfordert, uns mit seiner Geschichte kritisch auseinanderzusetzen, zumal Soziologen wie Andreas Reckwitz (2003, 2006, 2008) Kultur sehr wohl als Brückenkonzept rehabilitieren wollen und für eine umfassende Kulturalisierung der Soziologie plädieren. Dagegen halten Ethnologen wie Adam Kuper (1999, 2006) oder Chris Hann (2007) den Kulturbegriff für so unrettbar reifiziert, diffus und machtblind, dass sie ihn lieber abschaffen oder zumindest umfassend soziologisieren und durch eine präzisere Benennung der jeweils gemeinten symbolischen Codes oder sozialen Praktiken ersetzen wollen. Fächerübergreifender Dialog tut Not, und es gilt, einigen begrifflichen Schutt wegzuräumen.

Dazu will der vorliegende Aufsatz beitragen und zwar mit einem Blick auf die ethnologische Theoriegeschichte und insbesondere darauf, wie es zu jener Entsoziologisierung kam, die Kultur als Brückenkonzept problematisch gemacht hat. Der Schwerpunkt liegt dabei hier zunächst auf Entwicklungen in der amerikanischen Ethnologie, die bestimmte Vorstellungen von Kultur weit über die Fachgrenzen hinaus popularisiert und sich nicht zufällig als Cultural Anthropology bezeichnet hat. ${ }^{1}$ Andreas Reckwitz' Überblick über die ethnologische Kulturdiskussion (2000: insbes. 64ff; 2008: 15ff) ist einem meiner Meinung nach problematischen Fortschrittsnarrativ verpflichtet, an dessen Ende die allmähliche Durchsetzung einer Bedeutungssysteme und Kollektive entkoppelnden „Kontingenzperspektive“ steht. ${ }^{2}$ Für Reckwitz bietet vor allem Clifford Geertz' interpretativer Kulturbegriff fruchtbare Anknüpfungspunkte für die Soziologie, während ich Geertz' Arbeiten viel stärker in einer idealistischen, entsoziologisierenden Tradition von Kulturanalyse sehe, die der Forschungskooperation von Ethnologie und Soziologie wenig förderlich ist. Meine Skepsis teilen andere Ethnologen, deren Positionen ich im zweiten Teil dieses Aufsatzes diskutiere. Wie eine ,Soziologisierung“ des Kulturbegriffs aussehen könnte, die nicht zu einer allumfassenden „Kulturalisierung“ des Sozialen

1 Damit grenzte sich die amerikanische Ethnologie von der stärker soziologisch geprägten britischen Social Anthropology ab. In erster Linie diente und dient die Bezeichnung Cultural Anthropology allerdings zur Positionierung der Ethnologie im Rahmen der anderen Teildisziplinen ,physical anthropology“, „linguistic anthropology“ und „,archeology“, die in den USA gemeinhin mit der „cultural anthropology" in einem einzigen Universitätsinstitut vereint waren (und auch heute oft noch sind).

2 Vgl. auch die Sammelbände von Hörning und Reuter 2004 sowie Moebius und Quadflieg 2006 und Hauck 2006 zu soziologischen Perspektiven auf ethnologische Kulturtheorien. 
führt, sondern „Kultur“ als Arena von machtförmigen Aushandlungsprozessen begreift, bleibt eine offene Frage, mit der dieser Aufsatz schließt. ${ }^{3}$

\section{Ausgangspunkte. Edward Tylor und Franz Boas}

Ein nützlicher Ausgangspunkt für eine Rekapitulation der Geschichte ethnologischer Kulturkonzepte sind die Überlegungen zweier Gründungsväter des Fachs - des britischen Evolutionisten und Begründers der Social Anthropology Edward Tylor (1832-1917) und des deutschamerikanischen Ethnologen und Initiators der Cultural Anthropology Franz Boas (1858-1942). ${ }^{4}$ Boas gilt gemeinhin als Begründer des sogenannten Kulturrelativismus, der die Gleichwertigkeit aller menschlichen Kulturen betont und die Möglichkeit eines extern-wertenden Beobachterstandpunkts in Frage stellt. Allerdings ist Boas' theoretische Ausrichtung treffender mit „historischem Partikularismus“ bezeichnet, und Boas stand älteren diffusionistischen Überlegungen und Fragen des Kulturkontakts weit näher als seine Schüler, die die Geschlossenheit der Einzelkulturen betonten.

Boas' und Tylors' Kulturkonzepte gewinnen Kontur, wenn man herausarbeitet, gegen welche Vorstellungen sie einst gerichtet waren. Tylor wählte für sein 1871 veröffentlichtes Hauptwerk programmatisch den Titel Primitive Culture, ein doppelsinniger Titel, der auf ,ursprüngliche, uranfängliche Kultur“ ebenso verweist wie auf die „Kultur der Primitiven / Wilden“. Im Tylorschen Großbritannien war „culture“ gemeinhin mit „Hochkultur“ assoziiert, während weder die englische Arbeiterklasse noch die außereuropäischen fremden Völker als genuine Kulturträger galten. Der englische Dichter und Literaturkritiker Matthew Arnold hatte seine Überlegungen zur Gefährdung der Nation durch Massenkultur unter dem Titel Culture and Anarchy (1869) veröffentlicht, ${ }^{5}$ worauf Tylors zwei Jahre später erschienene Primitive Culture indirekt Bezug nahm. Tylors immer wieder zitierte Definition von Kultur grenzte sich von einem eingeschränkten Hochkultur-Verständnis ab und bestimmte Kultur als

„jenes komplexe Ganze, welches Wissen, Glaube, Kunst, Moral, Recht, Sitte und Brauch und alle anderen Fähigkeiten und Gewohnheiten einschließt, welche der Mensch als Mitglied der Gesellschaft erworben hat" (zitiert nach Kohl 1993: 130).

In dieser kumulativen Definition umfasste Kultur also Wissenschaft, Religion und Kunst, aber auch ganz allgemein Werte und Normen sowie technische Fertigkeiten und die materielle

3 Eine Anmerkung zum wissenschaftsbiographischen Hintergrund dieses Artikels sei hier gestattet. Ich selbst habe in den 1970er Jahren in Göttingen Soziologie studiert und schließlich mit einer Arbeit über indianische Arbeitsmigranten in Hannover in Soziologie promoviert. Danach war ich Mitarbeiterin beim bereits erwähnten Mühlmann-Schüler Georg Elwert am Institut für Ethnologie an der FU Berlin. Habilitiert habe ich mich dann dort im Fach Ethnologie und arbeite - nach einer Zwischenstation in Frankfurt am Main - in Mainz wiederum an einem der ethnosoziologischen Tradition verpflichteten Institut. Ich wurde auf diesem beruflichen Weg oft mit den Trennlinien zwischen den Fächern konfrontiert. Für viele Ethnologen war und bin ich bis heute keine ,,richtige“ Ethnologin, sondern eigentlich eine Soziologin; für die Soziologen wiederum ist, was ich schreibe, viel zu ethnologisch. Der vorliegende Aufsatz entstand aus Vorträgen, die ich im Herbst 2007 an der Johannes Gutenberg-Universität Mainz in einer interdisziplinären Ringvorlesung „Kultur. Ein (Un-)Begriff und seine Dimensionen“ und auf der Tagung „Historische Kulturwissenschaften. Konzepte und Methoden“ gehalten habe. Ich danke den Veranstaltern und Diskutanten für ihre Diskussionsbeiträge. Für eine freundlich-kritische Lektüre meines Manuskripts und vielfältige Anregungen gebührt insbesondere Britta Duelke, Mirco Göpfert, Stefan Hirschauer und Eva Spies sowie der interdisziplinären Arbeitsgruppe „Post-culture: doing difference“ an der Universität Mainz Dank.

4 Einen nützlichen Überblick über ethnologische Kulturtheorien bietet Kohl 1993: 129ff, eine knappe Zusammenfassung Lentz 2001.

5 Vgl. dazu auch Kuper 1999: 36ff sowie zur Beziehung zwischen Arnold und Tylor ebda: 59 f; zu Tylor und anderen Evolutionisten vgl. Petermann 2004: 463ff. 
Lebensweise. Kultur ist kollektiv, nicht Produkt genialer Individuen, und sie ist nicht natürlich gegeben, sondern gesellschaftlich geschaffen. Dabei geht es Tylor um Kultur im Singular, als „Zivilisation“, die sich im Lauf der Menschheitsgeschichte von einfachen zu immer komplexeren Formen entwickelt hat. Der Gegenbegriff dazu war offensichtlich die Natur, die der Mensch mittels der Kultur zunehmend zu beherrschen verstand.

Für Franz Boas, den jüdischen Emigranten aus Minden, der bei Rudolf Virchow und Adolf Bastian in Berlin habilitiert und am Berliner Völkerkundemuseum gearbeitet hatte, bis er dann 1886 ganz in die USA übersiedelte und dort zum Begründer der amerikanischen Cultural Anthropology wurde, war der entscheidende Gegenbegriff zu Kultur Rasse. ${ }^{6}$ Insofern sein Rassebegriff naturwissenschaftlich-biologisch geprägt war, grenzte auch Boas Kultur von Natur ab. Jedenfalls war er überzeugt, dass nicht die menschliche Physis, sondern geschichtlich gewordene und von Menschen gemachte kulturelle Einflüsse die Lebensweise prägten. Rassen, so postulierte Boas (1911), seien grundsätzlich vermischt und instabil, und der Körperbau habe keine Beziehung zu Mentalität, Charakter, Ausdrucksweise oder anderen Eigenschaften. Jede Gleichsetzung von Rasse, Kultur und Sprache, aber auch Umweltdeterminismus lehnte Boas ab. Kultur war zwar Instrument in der Auseinandersetzung mit je spezifischen natürlichen Umwelten, aber ebenso durch Migration und kulturellen Austausch zwischen benachbarten Gruppen geprägt - eine Vorstellung, die eng an das von den Berliner Museumsethnologen geprägten Konzept der Kulturkreise anschloss. ${ }^{7}$

Boas betonte verschiedentlich, dass es keine kulturbegründete Hierarchie zwischen unterschiedlichen Gesellschaften und keine geradlinige geschichtliche Höherentwicklung von Kultur gebe. Jede Gruppe sei in ihrer eigenen Lebensweise besonders und müsse in ihrer je konkreten Geschichte verstanden werden. Insofern pluralisierte Boas den Kulturbegriff und bereitete auf diese Weise den später von seinen Schülern und vor allem Schülerinnen propagierten Kulturrelativismus vor. Aber bis in die 1930er Jahre hinein, so insistiert jedenfalls Adam Kuper (1999: 62), habe Boas keinen holistischen Kulturbegriff entwickelt, Kultur also nicht unbedingt als integriertes und abgeschlossenes Ganzes verstanden, sondern sei eher noch dem additiven Kulturverständnis der Berliner Diffusionisten verpflichtet gewesen.

In gewisser Weise spiegeln sich in Tylors und Boas' unterschiedlichen Ansätzen zwei ältere europäische Traditionsstränge wider, die die Kulturdiskussion immer wieder beeinflusst haben: zum einen Kant und andere Aufklärungsphilosophen, die den Gedanken einer universalen Zivilisation (Kultur „,im Singular") und des Fortschritts propagierten; zum anderen Herder, Rousseau und verwandte Gelehrte, die just diese Zivilisations- und Fortschrittsvorstellungen kritisierten und die die jeweils spezifische (nationale) Kultur des (einfachen) Volks gegenüber der internationalen höfischen Zivilisation aufwerteten und damit Kultur pluralisierten. Auch Herder ging nicht von der Abgeschlossenheit von Kulturen aus, wohl aber von einer grundlegenden Einheit von Volk, Sprache und Kultur - ein Gedanke, den dann insbesondere Boas' Schüler aufgreifen. ${ }^{8}$

\section{Von „Zivilisation“ zu „Kulturen“. Die amerikanischen Kulturrelativisten}

Edward Sapir (1884-1939), ein Sohn litauisch-jüdischer Immigranten, der sein Studium an der Columbia Universität in New York absolvierte und 1907 bei Boas promovierte, war vermutlich einer der ersten Boas-Schüler, der Herders Gedanken von einer Pluralität von Kulturen und „Volksgeist(ern)“ explizit aufgriff. In einem 1924 veröffentlichten Aufsatz mit dem programmatischen Titel „Culture, genuine and spurious“ unterschied Sapir drei Verständnisse von

6 Zu Boas vgl. u.a. Stocking 1974, Dürr et al 1992 und Petermann 2004: 643ff.

7 Zum „Kulturkreis“-Konzept vgl. den informativen Überblicksartikel von Zitelmann (2001).

8 Zum Kulturkonzept bei Herder und Kant vgl. u.a. Petermann 2004: 304ff und Hauck 2006: $20 \mathrm{ff}$. 
Kultur - als Ensemble von Kulturtechniken bzw. technische Zivilisation, als individuelle Kultiviertheit (eine Anspielung auf den erwähnten Matthew Arnold) und schließlich als ,,,spirit' or ,genius' of a people“ (1924: 405). Zukunftsweisend für die Ethnologie, so Sapir, sei nur dieses dritte Verständnis von Kultur als ,the spiritual possessions of the group [...], those general attitudes, views of life, and specific manifestations of civilization that give a particular people its distinctive place in the world“ (1924: 405). Ethnologen sollten sich künftig also nur noch für die spirituell bedeutungsvollen und die Völker voneinander unterscheidenden Elemente der Zivilisation interessieren.

Sapir verwahrte sich gegen die evolutionistische Hierarchisierung verschiedener Kulturstufen, entwickelte aber durchaus ein normatives Verständnis von „echter“ Kultur:

„The genuine culture is [...] inherently harmonious, balanced, self-satisfactory. It is the expression of a richly varied and yet somehow unified and consistent attitude toward life [...] a culture in which nothing is spiritually meaningless, in which no part of the general functioning brings with it a sense of frustration. "(1924: 410)

Eine solchermaßen unentfremdete und ganzheitliche Kultur sei besonders ausgeprägt in kleineren autonomen Gruppen mit geringer Arbeitsteilung, deren Mitglieder durch direkten und intensiven „spiritual contact“ (1924: 426) miteinander verbunden seien und in denen auch die überlebensnotwendigen ökonomischen Tätigkeiten geistig durchdrungen blieben. Sapir kritisierte den Materialismus der amerikanischen Gesellschaft, in der die Mehrheit der Mitglieder ihre geistigen Bedürfnisse dem zivilisatorischen Fortschritt hätten opfern müssen: „Part of the time, we are dray horses; the rest of the time we are listless consumers of goods which have received no least impress of our personality“ (1924: 417). Dabei war seine Argumentation über das Verhältnis von Individuen und Kulturgemeinschaft ambivalent. Einerseits ließ er Kulturen als Kollektivsubjekte auftreten: „great cultures“ seien „healthy spiritual organisms“, die wie Pflanzen wüchsen und jedes Blatt mit ihrem Saft durchtränkten (1924: 410ff). Andererseits betonte er die Rolle individueller Kreativität und aktiver Aneignung des kulturellen Erbes durch die Mitglieder einer Kultur (1924: 418ff).

Was bei Sapir noch in der Schwebe blieb - mal akzentuierte er Kultur als ein integriertes geistiges Gebilde und eine kollektive Wertegemeinschaft, mal sah er Kultur als Produkt individuellen schöpferischen Handelns -, löste sich bei anderen Boas-Schüler(inne)n in einem recht naiven Kulturdeterminismus auf. Ruth Benedict (1887-1948), neben Margaret Mead die berühmteste Doktorandin von Boas und seinerzeit eine ethnologische Bestsellerautorin, entwickelte in Patterns of Culture (1934) ein dezidiert idealistisches Konzept von Kultur. Sie griff Anregungen aus der Gestaltpsychologie ebenso wie Oswald Spenglers Idee vom Wachstum und Untergang von Kulturen auf und begriff Kulturen als integrierte und jeweils durch einen Grundgedanken geprägte Ganzheiten. An den harten Fakten der ökonomischen Subsistenzgewinnung und der sozialen und politischen Organisation von Gesellschaften kaum interessiert, definierte Benedict Kulturen vor allem als konsistente Denk-, Fühl- und Handlungsmuster. Jede einzelne Kultur, so Benedict, treffe aus einem universellen „Kreisbogen“ verfügbarer Möglichkeiten eine Auswahl und verflechte diese ausgewählten Kulturelemente dann in komplexer Weise miteinander. Das „Ganze“ einer Kultur bestimme ihre Einzelelemente, vergleichbar mit einem künstlerischen Stil, einer Gestalt (1946). Einzelkulturen würden sich um dominante Leitmotive gruppieren, die den Angehörigen dieser Kultur aber weder notwendig bewusst sein müssten noch ohne Weiteres verändert werden könnten (1932: 4).

Hatte Boas noch kulturellen Austausch und Vermischung zwischen benachbarten Gruppen betont, so stand nun bei Benedict die interne Integration und Abgeschlossenheit der Einzelkultur im Mittelpunkt. Die unterschiedlichen Kulturmuster und Weltsichten, so Benedict, seien inkommensurabel; sie prägten die individuellen „Normal“-Typen einer Gesellschaft. Oder an- 
ders ausgedrückt: als „normal“ gelte, was in einer Kultur den akzeptierten Verhaltens- und Denkmustern entspräche oder was wertgeschätzt würde; als unnormal oder inakzeptabel hingegen würde angesehen, was in anderen Kulturen als ,normal“ Geltung habe - ein Gedanke, der später unter dem Stichwort Kulturrelativismus popularisiert wurde. Sehr viel stärker auch als Sapir betonte Benedict die prägende Kraft der Kultur(en), in die die Individuen hineingeboren und -sozialisiert würden. In gängigen Ethnologiegeschichten ${ }^{9}$ werden die Ansätze von Ruth Benedict, Margaret Mead und einigen anderen auch meist unter der Überschrift „Culture and Personality“ zu einer Schule zusammengefasst, die, wie der Name andeutet, Kultur als persönlichkeitsdeterminierend verstand - ein Gedanke, der außerhalb der Ethnologie rasch popularisiert wurde und den Ayşe Çaglar (1990) treffend in der Metapher ,the prison house of culture“, dem „Kulturgefängnis“, polemisch pointiert.

Bei den Boas-Schülern trennte sich also das Kulturkonzept von seinem älteren universalistischen Anspruch und vom Fortschrittsdogma des Evolutionismus und wurde mentalisiert, pluralisiert und, was die Vorstellung interner Kohärenz betrifft, homogenisiert. In Verbindung mit der Vorstellung einer klaren territorialen Verankerung dieser Einzelkulturen und mit Anleihen bei Frobenius' Kulturkreisen ging dieses Kulturkonzept dann auch in die amerikanische Variante des sogenannten ,culture areas“-Ansatzes, der Kulturareallehre von Clark Wissler und Melville Herskovits ein, die wiederum die Vorlage für Samuel Huntingtons (1993) angeblich miteinander konfligierende ,civilisations“ bot. $^{10}$

\section{Kultur versus Gesellschaft. Parsons Programm einer Arbeitsteilung zwischen Ethnologie und Soziologie}

Alfred L. Kroeber (1876-1960), Boas’ erster Doktorand und seit 1919 Ethnologieprofessor in Berkeley, betrachtete in seiner Theorie von Kultur als „Superorganismus“ den Menschen nur noch als Träger oder Ausführenden von Kulturmustern. Er propagierte diese Vorstellung übrigens schon in einem 1917 veröffentlichten Aufsatz; unter anderem Edward Sapir (1917) wies sie als quasi-religiöser Sozialdeterminismus zurück, während Ruth Benedicts organizistische Vorstellungen von Kultur daran anknüpften. Kroebers bekannteste Arbeit zu Kulturkonzepten entstand aber erst fünfunddreißig Jahre später, als er gemeinsam mit dem Harvard-Professor für Ethnologie Clyde Kluckhohn (1905-60) - ausnahmsweise kein Boasianer - ein Übersichtswerk über immer zahlreicher gewordene ethnologische Kulturdefinitionen veröffentlichte. In Tylors Definition sahen Kroeber und Kluckhohn (1952) den Durchbruch zu einem ethnologisch-wissenschaftlichen Kulturverständnis, kritisierten aber, dass er Kultur nur als additive Liste von Einzelaspekten darstelle. An Kroebers Konzept des „Superorganismus“ anknüpfend betonten sie, Kultur müsse vielmehr als integriertes und strukturiertes Ganzes begriffen werden. Vor allem gelte es, zwischen sozialem System und Kultur klar zu unterscheiden und Kultur als symbolisches System zu fassen, das Verhalten anleitet:

„Culture consists of patterns, explicit and implicit, of and for behavior acquired and transmitted by symbols. [...] [T] he essential core of culture consists of traditional [...] ideas and especially their attached values " (1952: 181).

In dieser Definition spiegelt sich die Auseinandersetzung mit Talcott Parsons (1902-1979), der 1946 das interdisziplinäre Department of Social Relations for Interdisciplinary Social Science Studies an der Harvard University gegründet hatte. Neben Soziologen und Psycholo-

9 Vgl. z.B. Stocking 1986 sowie Eriksen und Nielsen 2001: $61 \mathrm{ff}$.

10 Zur Kulturareallehre vgl. die kompakte Darstellung bei Petermann 2004: 654ff. Huntington verwendet den Begriff ,civilisations“ gleichbedeutend zu Kulturkreisen, nicht aber zum oben skizzierten universalistischen Zivilisationskonzept; sein Kulturverständnis knüpft eng an das von Ruth Benedict und anderen Kulturrelativisten an. 
gen arbeiteten in dieser Abteilung auch Ethnologen wie Clyde Kluckhohn und seine Frau Florence. Der Aufbau des Department spiegelte Parsons Plan, positivistische und idealistische soziologische Theorieansätze in einer umfassenden Handlungstheorie zu integrieren. In The Social System (1951) postulierte Parsons, das allgemeine „Handlungssystem“ bestehe aus miteinander verknüpften Sub-Systemen - dem sozialen, kulturellen und individuell-biologischen und psychologischen System -, denen sich vernünftigerweise auch die Arbeitsteilung in den Sozialwissenschaften anpassen sollte. Die Psychologie sei für das Individuum zuständig, die Soziologie für das soziale System und die Ethnologie für die Kultur.

Ein solches arbeitsteiliges Modell setze allerdings eine weitaus engere Definition des Gegenstands der Ethnologie - Kultur(en) - voraus, als bisher von den Fachvertretern propagiert worden sei. „Cultural objects are symbolic elements of the cultural tradition, ideas or beliefs, expressive symbols or value patterns", so Parsons (1951: 4), und die Ethnologie sollte entsprechend die Entstehung und Veränderung dieser symbolisch vermittelten Wertesysteme und Weltsichten erforschen. Doch Kluckhohn und Kroeber hatten Bedenken, denn Parsons enge Kulturdefinition würde traditionelle Arbeitsgebiete der Ethnologie wie z.B. die Archäologie und die physische Anthropologie (in den USA klassischer Bestandteil der Ethnologie) und das Interesse an Geschichte in Frage stellen. „In particular", so Kroeber und Kluckhohn (1952: 136), ,we are resistant to his [Parson's] absorbing into ,social systems' abstracted elements which we think are better viewed as part of the totality of culture“. Doch später schlossen sie sich der Parsonsschen Definition von Kultur als Symbolsystem an und plädierten für die vorgeschlagene Arbeitsteilung zwischen Soziologie, Psychologie und Ethnologie. Kroeber und Parsons formulierten diese Übereinkunft später nochmals zugespitzt in einem in der American Sociological Review veröffentlichten Manifest:

„,We suggest [...] to define the concept culture for most usages more narrowly than has generally been the case in the American anthropological tradition, restricting its reference to transmitted and created content and patterns of values, ideas, and other symbolic-meaningful systems as factors in the shaping of human behavior and the artifacts produced through behavior. On the other hand, we suggest that the term society - or more generally, social system - be used to designate the specifically relational system of interaction among individuals and collectivities. "(Kroeber / Parsons 1958: 583).

Kultur und Gesellschaft stünden zwar miteinander in Beziehung, seien aber als Untersuchungsgegenstände voneinander zu differenzieren: ,[T] hey are distinct systems in that they abstract or select two analytically distinct sets of components from the same concrete phenomena. [...] [T] he order of relationships within one is independent from that in the other" (1958: 582). Damit war der Weg für eine gesellschaftsfreie Definition von Kultur, die Konzentration auf Werte und Weltbilder statt Handlungen und Institutionen sowie die Abstraktion von Materialität und Macht frei. Bezeichnenderweise liest Reckwitz (2008: 24 f, 79 f) dasselbe Manifest, das ich quasi als Todesstoß einer soziologisch informierten Kulturanalyse ansehe, als begrüßenswerten Schritt in Richtung auf eine „Kontigenzperspektive“ - ein Verständnis von Kultur als ,symbolischen Ordnungen“, die nicht unbedingt mit einem bestimmten Trägerkollektiv verbunden sein müssen. Reckwitz übersieht dabei meines Erachtens, dass die von Parsons geforderte Kulturanalyse in der Hand der Ethnologen de facto weiterhin die Deckungsgleichheit von Symbolsystemen und sozialen Gemeinschaften unterstellte und durchaus dem oben skizzierten kulturrelativistischen totalitätsorientierten Kulturbegriff verpflichtet blieb. Auch die tradierte Zuständigkeit von Ethnologen für ,fremde“ Kulturen und der Soziologie für ,moderne“ Gesellschaft wurde von Parsons und Kroeber nicht wirklich in Frage gestellt.

In Großbritannien entwickelte sich die Ethnologie übrigens beinahe zeitgleich in die entgegengesetzte Richtung, nicht zuletzt auch in bewusster Konkurrenz zu und Abgrenzung von 
den amerikanischen Entwicklungen. ${ }^{11}$ Für A. R. Radcliffe-Brown, einen der damals federführenden britischen Ethnologen, sollte die ,social anthropology“ ein Teil der vergleichenden Soziologie sein $(1952: 3,189)$, und die ethnologischen Untersuchungseinheiten gesellschaftlich-historisch, nicht „kulturell“ definiert werden. „We do not observe , a culture'“, insistierte Radcliffe-Brown, ,since that word denotes, not any concrete reality, but an abstraction, and as it is commonly used a vague abstraction“" (1952: 190). Ähnlich äußerte sich vier Jahrzehnte später Jack Goody und setzte den europäischen Weg der Sozialanthropologie explizit den Parsonsschen Vorgaben und der amerikanischen Kulturanthropologie entgegen. Ethnologie dürfe sich keineswegs auf ein Studium von Kultur als Symbolsystemen beschränken, nicht zuletzt deshalb nicht, weil Kulturen nicht klar voneinander abgegrenzt und nicht isoliert von sozialen Beziehungen und materiellen Phänomenen analysiert werden könnten (1994: 251).

\section{Kultur als Text. Clifford Geertz' Entsoziologisierung des Kulturbegriffs}

Einer der berühmtesten Doktoranden aus Parsons Department of Social Relations ist Clifford Geertz (1926-2006). Seine Überlegungen zu Kultur als „Bedeutungsgewebe“ und „Text“ und zur Ethnographie als ,dichter Beschreibung“" wurden weit über die Fachgrenzen hinaus rezipiert und haben den ,,interpretive turn“ in den Geisteswissenschaften mit angestoßen (Bachmann-Medick 2006: 48ff). Auch für Soziologen wie Andreas Reckwitz ist Geertz der Ethnologe, der die meisten Anknüpfungspunkte bietet, um die Soziologie zu „kulturalisieren“.

Geertz gilt gemeinhin als „Weberianer“ und Hermeneutiker, der sich gegen den damals stark naturwissenschaftlich definierten Strukturfunktionalismus in der Ethnologie wandte. Dass Geertz aber auch von seiner Mitarbeit in Parsons' kulturvergleichenden Forschungsprojekten und ihrer symbolorientierten Kulturdefinition beeinflusst wurde, ist weniger bekannt.

Geertz' theoretische Perspektiven haben sich im Lauf seines langen wissenschaftlichen Wirkens verändert. ${ }^{12}$ Hier soll es nur um den in den 1970er Jahren entwickelten interpretativen Kulturbegriff gehen, der - so jedenfalls meine These - die von Parsons eingeleitete problematische Entsoziologisierung der Kultur vorantrieb. In seinem programmatischen Aufsatz „Thick description: toward an interpretative theory of culture“ (1973; deutsch 1987) formulierte Geertz die Grundelemente seines semiotisch-textualistischen Kulturverständnisses. Kultur sei der zentrale Begriff der Ethnologie, ,um den herum sich die gesamte Ethnologie als Fach bildete“ (1987: 8). Er müsse aber, so Geertz ganz im Sinne der Parsonsschen Arbeitsteilung zwischen Ethnologie und Soziologie, enger gefasst werden, als das gemeinhin der Fall sei, nämlich nicht wie bei Tylor und anderen Ethnologen in seinem Gefolge additiv-holistisch, die gesamte Lebensweise fassend. „Der Kulturbegriff, den ich vertrete“, so Geertz weiter,

„, ist wesentlich ein semiotischer. Ich meine mit Max Weber, daß der Mensch ein Wesen ist, das in selbstgesponnene Bedeutungsgewebe verstrickt ist, wobei ich Kultur als dieses Gewebe ansehe. Ihre Untersuchung ist daher keine experimentelle Wissenschaft, die nach Gesetzen sucht, sondern eine interpretierende, die nach Bedeutungen sucht. "(1987: 9)

11 Natürlich erschöpfte sich nicht die gesamte amerikanische Ethnologie in der kulturanthropologischen Richtung der Boas-Schüler; zeitgleich entwickelte sich - zunächst unter Federführung der Neoevolutionisten wie etwa Julian Steward - mit Eric Wolf und Sidney Mintz und ihren Kollegen und Schülern eine materialistisch-gesellschaftskritische ,Schule“, die Kultur mit Machtprozessen zusammendachte und die Analyse von Sozialstrukturen und politischen Prozessen keineswegs an die Soziologie zu delegieren bereit war. Vgl. dazu z.B. Layton 1997: 127ff und Petermann 2004: 734ff.

12 Zur theoretischen Entwicklung von Geertz und seinen unterschiedlichen empirischen Forschungen vgl. seine Autobiographie (Geertz 1995) sowie Adam Kupers kritischen Überblick (1999: 75ff). Zu Geertz' Kulturkonzept vgl. auch Gottowik 1997: 205ff, Reckwitz 2000: 445ff und Bachmann-Medick 2006: 60ff. 
An anderer Stelle definiert Geertz Kultur als Gefüge von Symbolsystemen - Ideologien, Religion, Kunst, Wissenschaft, Ethik und common sense -, mit deren Hilfe sich Menschen orientieren und ihren Erfahrungen Sinn verleihen, und schreibt von Kultur als den ,symbolischen Dimensionen sozialen Handelns“ (1987: 43). Ethnographie habe es demzufolge mit der Interpretation von bedeutungsvollem Handeln zu tun, mit der Entzifferung des „Texts“ der Kultur. Der Ethnologe müsse Handlungen in fremden Kulturen - die Geertz in der kulturrelativistischen Tradition als Untersuchungseinheiten auffasst - als Teil eines ganzen Gefüges von Bedeutungen, als Zeichen in einem Zeichensystem verstehen. Insofern sei Ethnographie „dichte Beschreibung":

„Das, womit der Ethnograph tatsächlich zu tun hat [...] ist eine Vielfalt komplexer, oft übereinandergelagerter oder ineinander verwobener Vorstellungsstrukturen, die fremdartig und zugleich ungeordnet und verborgen sind und die er zunächst einmal irgendwie fassen muß.[...] Ethnographie betreiben gleicht dem Versuch, ein Manuskript zu lesen (im Sinne von, eine Lesart entwickeln'), das fremdartig, verblaßt, unvollständig, voll von Widersprüchen, fragwürdigen Verbesserungen und tendenziösen Kommentaren ist, aber nicht in konventionellen Lautzeichen, sondern in vergänglichen Beispielen geformten Verhaltens geschrieben ist. "(1987: 15)

Die „Kultur als Text“-Metapher darf also nicht im Sinne des Mentalismus und der kognitiven Ethnologie als Konzentration auf die Weltbilder und Symbolsysteme, wie sie die Mitglieder einer Kultur explizieren könnten, missverstanden werden. Für Geertz besteht Kultur zwar aus „Ideen“, aber sie „existiert [...] nicht in den Köpfen“, jedenfalls nicht in den Köpfen von Individuen, sondern als „öffentliches Dokument“(1987: 16). Es geht nicht um das individuelle Wissen und Handlungsintentionen oder um die Auseinandersetzung einzelner Mitglieder einer Kultur mit ihren Wertsystemen, sondern um die kollektiv geteilten Symbolsysteme, die in öffentlichen Handlungen sichtbar werden. Oder, wie Geertz im Anschluss an Paul Ricœur formuliert, es sind die kulturellen Formen, die sich in sozialem Handeln ausdrücken, die der Ethnograph dann als „sozialen Diskurs“ entziffert und niederschreibt (1987: 28). ${ }^{13}$

Zwar räumt Geertz den Selbstinterpretationen der Handelnden heuristischen Stellenwert ein: „wir interpretieren zunächst, was unsere Informanten meinen, oder was sie unserer Auffassung nach meinen, und systematisieren diese Interpretationen dann" (1987: 22). Letztlich aber sind Selbstsicht und Debatten der Mitglieder einer Kultur für das Geertzsche Projekt irrelevant. Wenn Geertz schreibt, dass die „Kultur eines Volks [...] aus einem Ensemble von Texten [besteht], die ihrerseits wieder Ensembles sind, und der Ethnologe [sich] bemüht [...], sie über die Schultern derjenigen, für die sie eigentlich gedacht sind, zu lesen“"(1987: 259), so postuliert er offensichtlich einen Interpretationsvorsprung des Ethnologen. ${ }^{14}$ Der „Zugang zur Gedankenwelt der von uns untersuchten Subjekte“ (1987: 35) wird nicht vorrangig durch Interviews und die Interpretation von Textzeugnissen erlangt, sondern durch teilnehmende Beobachtung bei öffentlichen Ereignissen. So bleibt der „native point of view“ - von Geertz durchaus im Singular gedacht, nicht als Vielfalt miteinander konkurrierender lokaler Perspektiven - ein Konstrukt des Ethnologen.

An diesem quasi-paternalistischen Anspruch, ein autoritatives Porträt einer fremden Kultur zu entwerfen, entzündete sich heftige Kritik. In der Writing Culture-Debatte unter amerikanischen Ethnologen wurde Geertz gewissermaßen zum Lieblingsfeind (ebenso wie Gründungs-

13 Zur Widersprüchlichkeit von Geertz’ Anleihen bei Ricoeur vgl. Gottowik 1997: 237ff.

$14 \mathrm{Zu}$ einer interessanten methodologischen Verteidigung dieses ethnographischen Verfahrens aus soziologischer Perspektive vgl. Amann und Hirschauer 1997: $21 \mathrm{ff}$. Hirschauer (2008) wirft Geertz denn auch nicht den unreflektierten Anspruch auf ein Deutungsmonopol vor, sondern Intellektualismus: Geertz gleiche soziale Praktiken viel zu stark an Aussagen und Deutungen intellektueller Praxis an. 
vater und Anreger) erkoren..$^{15}$ Geertz' an Parsons angelehnte Entsoziologisierung des Kulturbegriffs fand dagegen weniger Widerspruch. In einem frühen Aufsatz über den Nationalismus in den neuen postkolonialen Staaten setzte sich Geertz explizit mit Parsons' Verständnis von Kultur als handlungsleitendem Symbolsystem auseinander. Symbolsysteme seien für Parsons, so Geertz durchaus zustimmend, zugleich

„, a product and a determinant of social interaction, they are to the process of social life as a computer's program is to its operations, the genic helix to the development of the organism, the blueprint to the construction of the bridge, the score to the performance of the symphony" (1973: 250).

Das eigentliche Problem sei allerdings, wie denn die Beziehung zwischen den ,patterns of meaning" und dem ,concrete course of social life“ (1973: 250) genau zu fassen sei, und hier betonte Geertz weit stärker als Parsons die Eigendynamik der Symbolsysteme. Kultur sei „keine Instanz, der gesellschaftliche Ereignisse, Verhaltensweisen, Institutionen oder Prozesse zugeordnet werden könnten“ (1987: 21); sie könne nicht aus ihrer „Funktion“ für bestimmte soziale Prozesse heraus erklärt, sondern müsse als „Kontext“ begriffen werden, in dem soziales Handeln „verständlich“ werde. Adam Kuper sieht hier eine erste Abkehr vom Gesellschaftlichen zugunsten einer eher geisteswissenschaftlichen Fundierung der Ethnologie, die dann beim späten Geertz - insbesondere in seiner Arbeit über den balinesischen ,Theaterstaat" - immer deutlicher zutage trete:

„What Geertz offers in the end is an elegant endorsement of the project of interpretation, and he lends to this project the legitimacy of something that may be a science [...] As Geertz has distanced himself from social scientific approaches, he has come out as a traditional humanist. [...] He sharpened and refined the definition of culture, and then treated it in its own terms [...] as a symbolic system, working by way of metaphors, a mélange of texts. Ultimately, culture came to mean for Geertz something very like the culture of the old humanists: the epitome of the values that rule in a society, embodied most perfectly in the religious rituals and the high art of the elite. [...] Above all, Geertz' message is that culture is the essential element in the definition of human nature, and the dominant force in history. [...] Culture rules: indeed, high culture rules. " (Kuper 1999: 119f)

Man mag dieser polemischen Zuspitzung nicht folgen, sondern eher auf die Möglichkeit einer praxistheoretischen Lesart seines Kulturbegriffs verweisen, wie das etwa Sherry Ortner (1999) oder Doris Bachmann-Medick (2006: 75ff) tun. Auch Andreas Reckwitz sieht in Geertz vornehmlich einen ,Vertreter einer postphänomenologischen interpretativen Kulturtheorie mit handlungstheoretischem Grundriß“. Reckwitz konzediert aber, dass das Geertzsche Kulturverständnis ,,in ein textualistisches Modell umzuschlagen“ d droht, bei dem die „Textbedeutung“ nicht ,,von den Intentionen des Textproduzenten, sondern vom Sinnhorizont des Textinterpreten“, also dem Ethnologen, abhängt (2006: 469 f). In der Tat birgt die Metapher der „Kultur als Text“ das „Risiko einer ,Illusion der autonomen Symbole“" (Reckwitz 2006: 473). Aber besonders für Geisteswissenschaftler scheint Geertz' textualistisches Kulturkonzept attraktiver als jenes materialistisch-politökonomisch inspirierte Verständnis von Kultur als ,whole way of life" und „whole way of conflict“", wie es etwa der amerikanische Ethnologe Eric Wolf oder der britische Sozialhistoriker E. P. Thompson vorgeschlagen haben. ${ }^{16}$

15 Vgl. z.B. Clifford 1988 (zuerst 1983), Crapanzano 1986 und Sangren 1988.

16 Vgl. z.B. Eric Wolfs frühe Forderung, das Konzept abgeschlossener Kulturen zu überdenken (1982: $387 \mathrm{f}$ ). Für eine aufschlussreiche Zusammenfassung der Kulturkonzepte anglomarxistischer Historiker wie E.P. Thompson und anderen vgl. Medick 1982. Paradoxerweise machte aber gerade Hans Medick, der sich eher diesem soziologisch-materialistisch fundierten als einem geertzianisch-kulturalistischen Kulturverständnis anschließt, das Geertzsche Programm der ,dichten Beschreibung“ in Teilen der Geschichtswissenschaft populär (Medick 1984). 
Reckwitz (2008: 33 f) sieht Geertz als Leitfigur einer Wende hin zur ,sozialkonstruktivistischen Umdeutung“ von Kultur, die ,den Kultur- vom Gemeinschaftsbegriff“ löst (2008: $79 \mathrm{f}$ ). Doch wird die Beziehung zwischen den Interpretationsgemeinschaften, die bestimmte Symbole und Weltanschauungen als gemeinsamen ,öffentlichen (Kultur)Text“ deuten, und gesellschaftlichen (Interessens)Gruppen von Geertz nicht wirklich thematisiert. Schaut man sich seine Ethnographien an, so bleibt es bei als Gemeinschaften unterstellten „Kulturen“ als Analyseeinheiten. Geertz verweist zwar wiederholt auf die Komplexität, Widersprüchlichkeit und Überlagerung von Bedeutungsstrukturen und überwindet damit theoretisch die Benedictschen und andere klassisch-kulturrelativistischen Vorstellungen von Kulturen als geschlossenen Symbolsystemen. Aber die Entsoziologisierung seines Kulturbegriffs führt dazu, dass implizit doch wieder die Vorstellung einer Identität von einer spezifischen Gesellschaft (als Nation, Volk oder Ethnie gedacht) und jeweils einer spezifischen Kultur transportiert wird.

\section{Zwischenbilanz: das Container-Modell von Kultur und der „savage slot“6 der Ethnologie}

Halten wir in einer Zwischenbilanz das konzeptuelle Erbe der kulturrelativistischen Kulturanthropologen und ihres Kulturbegriffs fest. Prämissen dieses „klassischen“ Kulturkonzepts sind die meist unausgesprochenen Annahmen, dass die Welt ein Mosaik territorial verankerter, diskreter Kulturen ist - eine Art Container-Modell von Kulturen, das bereits in Herders Bild von Kulturen als diskreten „Kugeln“ angelegt ist; dass diese Kulturen im historischen Langzeitverlauf relativ stabil sind und dass intrakulturelle Variationen darum gegenüber interkulturellen Unterschieden vernachlässigt werden können. Abgeschlossenheit, Stabilität, Homogenität und Kohärenz sind Stichworte, in denen sich dieser Kulturbegriff zusammenfassen lässt. Die problematischen Blindstellen liegen auf der Hand: Variabilität und Konflikt werden ausgeblendet sowie Machtprozesse ignoriert; außerdem wird ein ,übersozialisiertes“ Individuum unterstellt, während ,,agency“ und Kreativität ausgeblendet bleiben; kultureller Wandel ist kaum erklärbar, es sei denn als Ergebnis von „Kulturkontakt“.${ }^{17}$ Für Geertz und die symbolisch-interpretative Ethnologie treffen die Vorwürfe der Überbetonung der Geschlossenheit der „Kulturen“ nur partiell zu; hier liegt der Beitrag zur Essentialisierung des Kulturbegriffs in der Ausblendung der Probleme von Grenzziehungen (wie werden gesellschaftliche Gruppen und kulturelle Bedeutungsstrukturen einander zugeordnet?) und im Risiko der Autonomisierung von Symbolsystemen.

Es sind Varianten des entsoziologisierten, ,klassischen“ Kulturkonzepts, die auch außerhalb der Wissenschaft populär wurden und auf die heute viele Politiker und Journalisten, aber auch Nichtregierungsorganisationen und soziale Bewegungen zurückgreifen, wenn es darum geht, etwa politische Instabilität und Staatszerfall in Afrika oder Konflikte mit Immigrantenkindern an westeuropäischen Schulen zu erklären oder die Integration der Türkei in die Europäische Union zu diskutieren. Alles scheint eine Frage der „Kultur“ bzw. kulturellen Differenz. ${ }^{18} \mathrm{Kul}-$ tur funktioniert hier gewissermaßen als nützlicher argumentativer Joker, der andere Begriffe ersetzen kann, wie Nation und Ethnie oder aber auch Rasse. In Südafrika zum Beispiel argumentierte die Apartheidsregierung stets mit Kulturunterschieden, wenn sie eigentlich „Rasse“ meinte (Boonzaier 1988, Thornton 1988, Kuper 1999: xiiff). Ähnliches lässt sich in „weißen“ Diskursen über Schwarze (und „schwarzen“ über Weiße) in den USA finden (Trouillot 2002: 45ff), aber auch in rechtsradikalen Argumentationen in Europa (Stolcke 1995, Hall 2004:

17 Diese Liste der Desiderata des klassischen ethnologischen Kulturbegriffs haben zahlreiche Autoren so oder ähnlich aufgestellt; vgl. z.B. Keesing 1987 und 1994, Brumann 1999 (der allerdings behauptet, die Kritik würde den ethnologischen Klassikern Unrecht tun) sowie Wimmer 2005: 7ff.

18 Allgemein zur inflationären Verwendung des Kulturbegriffs in der öffentlichen Diskussion vgl. Kaschuba 1995, Kuper 2006, Hann 2007 sowie Maderthaner und Musner 2007: 86ff. 
202ff). Und auch wo offen rassistische Argumente nicht mitschwingen, wird „Kultur“ oft quasi naturalisiert und das unterstellt, wofür früher „Rasse“ verantwortlich gemacht wurde: Menschen gelten dann qua Abstammung als Mitglied einer Kultur und können nicht anders handeln, als ihre Kultur es ihnen vorschreibt.

Warum konnte sich der ursprünglich antirassistisch intendierte Kulturbegriff derart verfestigen? Bei der Suche nach Antworten auf diese Frage verweist Michel-Rolph Trouillot auf den wissenschaftshistorischen und den politischen Kontext der Entwicklung des ethnologischen Kulturbegriffs in Nordamerika. Die Umstände der Institutionalisierung der amerikanischen Ethnologie in den 1920er Jahren hätten, so Trouillot, die Bedeutung von Kultur verschoben „from being a domain of analysis to being something out there" (2002: 42). Nicht-westliche Gebiete und Gruppen galten als „fundamentally different both in essence and in practice“ (2002: 42), die nicht mit denselben Methoden untersucht werden konnten wie westliche Gesellschaften. Die Ethnologen boten sich als Spezialisten für diesen ,savage slot" an (Trouillot 1991; 2002: 42). Ihre Untersuchungseinheiten grenzten sie nach demselben konzeptuellen Schema ab wie die Soziologen und Politikwissenschaftler, die im Sinne des methodologischen Nationalismus die Staatsgrenzen als quasi-natürliche Grenzen der von ihnen untersuchten Gesellschaften unterstellten. Ethnologen, so Trouillot, ,mimicked the state-centrism of the other social sciences, often assuming for these [non-Western] peoples a waterish version of the nation-state, the borders of which were alleged to be as obvious and as impermeable as those of the North Atlantic entities“ (2002: 42 f). Kulturen wurden so die selbstverständlichen Untersuchungseinheiten und als deckungsgleich mit Gesellschaften vorgestellt. ,Just as France or the United States obviously had one economy, one history, and one social life", so Trouillot, „the Iroquois, the Samoans, the Dobu, the Zuñi, or the Japanese for that matter, could have only one of these“" (2002: 43). Dabei erschienen die fremden Kulturen als klassenlose Gebilde: „For North American anthropologists, primitives became those who had no complexity, no class, no history that really mattered - because they had culture." (2002: 44) Die drastischen Vereinfachungen, so Trouillot, hätten es der Disziplin erlaubt, einen festen Platz in der akademischen Welt zu erobern. Ethnologen wurden eben zu Spezialisten für Kultur, und das Genre der Ethnographie, die zu schreiben das Initiationsritual in die Zunft darstellte, zementierte die Untersuchungseinheit „Kultur(en)“.

Kultur sei auch, so Trouillot weiter, implizit „rassifiziert“ worden. Boas hätte Rasse als biologische Tatsache aufgefasst, die dokumentiert, aber nicht weiter problematisiert werden musste. Weil auch die post-Boas'schen Ethnologen sich mit Rasse und Rassismus nicht beschäftigt hätten, so Trouillot weiter, sei der Kulturbegriff aus seiner ursprünglichen Beziehung als Gegenbegriff zu Rasse herausgelöst und zu einem entpolitisierten ,theoretical refuge“ geworden (2002: 47). Amerikanische Ethnologen hätten zwar Indianer, aber keine „Schwarzen“ untersucht und schon gar keine „Weißen“. Für Rasse und Rassismus waren die Soziologen zuständig, während das ethnologische Kulturkonzept durch seine Anbindung an scheinbar homogene, klassenlose und konfliktarme nicht-westliche Gesellschaften von Fragen nach Macht und Ausgrenzung freigehalten wurde.

Für die europäische Ethnologie und Soziologie treffen Trouillots Überlegungen freilich nur partiell zu. Eine Untersuchung der wissenschaftshistorischen und gesellschaftspolitischen Konstellationen, die hier die Rezeption des ,amerikanischen“ Kulturbegriffs bestimmt haben, 
steht noch aus. ${ }^{19}$ Über Trouillot hinausgehend wäre auch zu erörtern, ob nicht generell eine systemisch-funktionalistische Betrachtungsweise zur Essentialisierung der Untersuchungseinheiten führt, gleichgültig, ob diese nun als Kulturen oder Gesellschaften gefasst werden. Zumindest der Homogenisierungs-Vorwurf und die Kritik, Wandel und ,agency“ zu vernachlässigen, treffen auch auf den den Kulturbegriff vermeidenden strukturfunktionalistischen Ansatz von Radcliffe-Brown und die britische Social Anthropology zu. Dies weiter zu verfolgen, würde allerdings den Rahmen dieses Artikels sprengen, der nur das enger gesteckte Ziel hat, die Geschichte der Essentialisierung und Entsoziologisierung des Kulturkonzepts und seine rezente kritische Revision in der Ethnologie zu skizzieren.

\section{„Adieu culture“? Kritik und Revisionsvorschläge}

Mit „Abschied von der Kultur“ (ohne Fragezeichen) betitelte Trouillot (2002) seinen Artikel in programmatischer Absicht. Auch andere Ethnologen wie etwa Lila Abu-Lughod haben den klassischen Kulturbegriff radikal kritisiert. Diese Kritik rief wiederum diverse Revisions- und Rettungsvorschläge auf den Plan, nicht zuletzt auch praxistheoretische Reformulierungen, die das Kulturkonzept wieder anschlussfähig für die Soziologie machen könnten. Einige Stationen dieser rezenten ethnologischen Debatte um Kultur sollen im Folgenden skizziert werden.

\section{,Writing against culture "20}

Lila Abu-Lughod, eine amerikanisch-palästinensische Ethnologin, die lange Zeit in Ägypten gelebt hat, war eine der ersten, die vehement dafür argumentierte, den Kulturbegriff über Bord zu werfen. Kultur sei „the essential tool for making other“ (1991: 43) und erzwinge geradezu die hierarchische, machtbesetzte Unterscheidung zwischen dem Eigenen und dem Fremden. Sie argumentiere, so Abu-Lughod, aus der Sicht von Feministinnen und halfies, Menschen, die wie sie selbst „Zwischen den Kulturen“ stünden. Die halfie-Perspektive erlaube, die Unterscheidung zwischen „Wir“ und den „Anderen“ auf ihre Positionalität und Machtimplikationen hin zu befragen.

Indem Ethnologie kulturelle Differenz beschreibe und zur Erklärungsgrundlage gesellschaftlicher Phänomene mache, trage sie letztlich zur Konstruktion und Aufrechterhaltung eben dieser Differenz bei und sperre nicht-westliche Gruppen in dieser Fremdheit geradezu ein (Abu-Lughod 1991: 146). Im Interesse der Abgrenzbarkeit der Gruppen betone jede Argumentation mit „Kultur“ deren interne Kohärenz und Homogenität. Selbst wenn „Kultur“ in emanzipatorischer Absicht herangezogen würde, um neue Identitäten zu bilden, bliebe die Argumentation essentialistisch und zementiere Differenz. Von diesen Tendenzen könne der Begriff Kultur nicht gereinigt werden, und man müsse darum Strategien finden ,for writing against culture“ (1991: 147). Ethnographien des Besonderen (,ethnographies of the particular"), die auf Praxis, Strategien und Interessen fokussierten, statt in Bildern von kohärenten kulturellen Regelwerken befangen zu bleiben, seien der einzige Ausweg. Statt kulturelle Un-

19 Überlegungen, warum sich ,essentialized and racialized views of culture(s)“ (Trouillot 2002: 38) im europäischen Kontext von Migration und Exklusion für populäre Übernahmen anboten, finden sich bei Stolcke 1995; auch im Kontext von internationaler Politik und Entwicklungszusammenarbeit sind manche Akteure durchaus daran interessiert, Machtdifferentiale und politische Konflikte als Fragen von „Kultur“-Unterschieden zu redefinieren. Zu den binnenwissenschaftlichen Gründen der rezenten Hochkonjunktur von „Kultur“ in den Geistes- und Sozialwissenschaften vgl. Bachmann-Medicks (2006) Analyse der diversen , cultural turns“.

20 Abu-Lughod 1991. Dieser Aufsatztitel nimmt auf den Titel des die „postmoderne“ Ethnologie einläutenden Sammelbands Writing Culture (1986) von Clifford und Marcus Bezug, dessen Beiträge vor allem kritisch über die Rolle nachdenken, die Ethnologen als Autoren bei der Konstruktion ihres Gegenstands spielen. Der Doppelsinn „Kultur schreiben“ und „Kultur des Schreibens“ ist von den Herausgebern selbstverständlich intendiert. 
terschiede zwischen Großgruppen herauszuarbeiten, sollten die Individualität und unmittelbare Verstehbarkeit jedes einzelnen Individuums betont werden. Eine Vielzahl individueller Geschichten, so Abu-Lughods Überzeugung, würde Verbindungen statt kultureller Grenzen aufzeigen und darlegen, ,that others live as we perceive ourselves living, not as robots programmed with ,cultural' rules, but as people going through life agonizing over decisions, making mistakes [...] and finding moments of happiness“ (1991: 158) - ein Beitrag zu einem ,taktischen Humanismus“, der allerdings die grundsätzliche Positionierung der Ethnologie auf der Seite der „Herrschaft“ in einer Welt der Ungleichheit nicht überwinden könne (1991: 159).

\section{,Writing for culture “21}

Dass der klassische ethnologische Kulturbegriff politisch missbraucht werden könne, konzediert auch Christoph Brumann. Doch anders als Abu-Lughod ist er überzeugt, dass die problematischen Postulate von Abgeschlossenheit, Homogenität, Kohärenz und Dauerhaftigkeit sowie die essentialisierende Gleichsetzung von ethnischer Gruppe und Kultur dem Kulturbegriff nicht notwendig innewohnen. Nicht die klassischen Kulturdefinitionen hätten die Essentialisierung von „Kultur“ befördert, sondern die Traditionen ethnographischen Schreibens, die die Welt als ein Mosaik territorial abgegrenzter, intern homogener, dauerhafter Kulturen darstellen würden. Wenn Ethnologen aber an der politischen Debatte über Kultur als Experten teilnehmen wollten, dürfte sie den Kulturbegriff nicht verbannen, sondern müssten ihn reformulieren und stärken. Brumann schlägt darum vor, Kultur zu definieren als

,the set of specific learned routines (and / or their material and immaterial products) that are characteristic of a delineated group or people [...] The existence of any such culture presupposes that of other sets of routines shared by other groups of people, thus constituting different cultures [...] In identifying a culture, we have to abstract such a set of items from observed instances of thought and behavior, selecting that which occurs repeatedly rather than that which is singular. This is a mental operation that is not in principle different from, say, identifiying a style in individual works of art." (1999: 6)

Die Frage der Abgrenzung von Kulturen ist für Brumann eine Frage der Übereinstimmung von Merkmalsbündeln, d.h. von klar identifizierbaren Arten und Weisen des Fühlens, Denkens und Handelns. Drei Möglichkeiten der Verteilung von kulturellen Merkmalen seien theoretisch denkbar: erstens perfekter Gleichklang und Kovariation aller ausgewählten Merkmale, so dass sich zwei (oder mehrere) Kulturen eindeutig identifizieren ließen; zweitens eine Zufallsverteilung, in der gar keine abgegrenzten Kulturen erkennbar würden; und schließlich drittens das, was Brumann als Normalfall ansieht, eine Cluster-Bildung, bei der einige Kulturmerkmale überlappen und kovariieren, andere aber nicht. Wenn man nun zwischen Kernmerkmalen, die von allen Mitgliedern einer Kultur geteilt werden, und weniger zentralen Merkmalen unterscheide, sei Kultur einfach der Begriff, der diese Cluster von Kernmerkmalen bezeichnet. Dabei würde ein solches auf Beobachtung und Clusteranalyse gegründetes Kulturverständnis keineswegs vollkommene Homogenität und langfristige Stabilität unterstellen. Von - zum Beispiel - ,japanischer Kultur“ zu sprechen, sei letztlich nur eine praktische Abkürzung, um auszudrücken, dass es gewisse Routinen, Werte usw. gebe, die viele oder die meisten Japaner teilen würden, jenseits von Klassen, Geschlechtsunterschieden und anderen Differenzen; ,that which [...] [they] think, feel and do by virtue of having been in continuous social contact with other Japanese“" (1999: 7).

Hier wird nun aber ein zentrales Problem des positivistischen Kulturbegriffs von Brumann deutlich, nämlich die potentielle Beliebigkeit und Unerschöpflichkeit der kulturellen Inventare, die zur Definition einer Kultur herangezogen werden können. Das induktive Verfahren,

21 Brumann 1999. Der Titel nimmt explizit Bezug auf den Artikel von Abu-Lughod. 
das Brumann vorschlägt, lässt keine Hierarchisierung zu, sondern impliziert eine Rückkehr zu einem vorhermeneutischen Kulturbegriff, weil die Interpretationen der Mitglieder der Kultur selbst nicht thematisiert werden. Ungeklärt bleibt auch, in welchem Verhältnis „Kultur“ als Set von Routinen zu Gruppenbildungsprozessen steht. Ist Gruppenbildung vorausgesetzt, damit Akteure selbstbewusst Kultur abgrenzen? Was, wenn die Akteurs- und Beobachterdefinitionen zentraler Kulturmerkmale nicht übereinstimmen? ${ }^{22}$ Brumann fordert zu Recht, dass ein brauchbarer Kulturbegriff drei Einsichten unbedingt berücksichtigen müsse: 1. dass die soziale Reproduktion von Kultur niemals automatisch gegeben sei, sondern Machtprozesse bei der Herstellung von kulturellem Konsensus eine wichtige Rolle spielten; 2. dass Kultur nicht alles Handeln bestimme und die Individuen vollständig determiniere; und 3. dass Kultur nicht unbedingt an ethnische Grenzen gebunden sei und identitätsstiftend wirken müsse. ${ }^{23}$ Doch scheint mir, dass sein additiv analytisches, quasi-statistisches Kultur-als-Merkmalscluster-Konzept diesen Einsichten nicht gerecht werden kann.

\section{Kultur als Prozess der Aushandlung}

Diese Einsichten finden eher Eingang in Ansätzen, die Kultur(en) nicht durch einen festen, von allen Mitgliedern geteilten Kanon von Weltbildern, Normen und Praktiken definieren, sondern stattdessen als „Diskursfeld“ (Schiffauer 1999) oder Arena verstehen, auf der die zentralen Werte und Institutionen immer wieder neu ausgehandelt werden. Die kulturelle Gemeinsamkeit werde, so Schiffauer, jeweils nur temporär hergestellt. Sie konstituiert sich im Einverständnis über die Regeln, nach denen die Debatten geführt werden, durch die kollektive Erinnerung an bereits geführte Debatten und durch die gemeinsamen Streitgegenstände.

Andreas Wimmer, der einen ähnlichen Ansatz wie Schiffauer verfolgt, definiert Kultur ,als ein[en] offene[n] und instabile[n] Prozess des Aushandelns von Bedeutungen [...], der kognitiv kompetente Akteure in unterschiedlichen Interessenslagen zueinander in Beziehung setzt und bei einer Kompromissbildung zur sozialen Abschließung und entsprechenden kulturellen Grenzmarkierungen führt" (1996: 413). Wimmer schließt hier an die anti-parsonssche Tradition des Symbolischen Interaktionismus an und unterscheidet zwischen ,,verinnerlichter Kultur" oder Habitus, öffentlicher Kultur mit kollektiven Repräsentationen und Aushandlungsprozessen und schließlich dem Prozess sozialer Schließung und kultureller Distinktion. Mit dem von Bourdieu entlehnten Begriff des Habitus will Wimmer das fassen, was bei Brumann die gelernten Routinen sind - jene kulturellen Unterschiede, die jeder erlebt, wenn er etwa auf Reisen auf Menschen anderer Herkunft stößt. Als Habitus begreift Bourdieu die durch Sozialisation vermittelten Prädispositionen, die spezifische Handlungen, Wahrnehmungen und Interpretationen hervorbringen. Allerdings insistiert Wimmer abweichend von Bourdieu auf der universalen Kompetenz der Menschen, „Kosten und Nutzen gegeneinander abzuwägen und dabei die eigenen Interessen wahrzunehmen“ (1996: 407 f). Folglich sei niemand vollständig durch den Habitus determiniert. Die habituellen Schemata brächten entsprechend der unterschiedlichen sozialen Lagen verschiedene Weltdeutungen und symbolische Ordnungen hervor, die aber in einem Kommunikationsfeld aufeinander bezogen seien, in dem die Akteure, so Wimmer, jene Elemente eruierten, in denen sie alle ihre langfristigen Ziele wiedererkennen könnten. „Im alltäglichen Umgang der Akteure werden Situationsdefinitionen, Rollenzuweisungen, Handlungspläne und Normen des zwischenmenschlichen Verkehrs ausgehandelt" (1996: 409). Diese Aushandlung fände im Rahmen von situationsübergreifenden Überein-

22 Statistische Konsensanalysen, auf die Brumann verweist („Consensus analysis is a statistical model for determining whether there is a common culture behind informants' responses“, 1999: 8, Fn 11), können das Dilemma m.E. nicht wirklich lösen.

23 Zur Problematik der Gleichsetzung von Kultur und Ethnie und zur Diskussion über das Ethnienkonzept anhand afrikanischer Beispiele vgl. auch Lentz 1995. 
künften über die gültigen Regeln des Handelns und Darstellens statt und münde in einem „symbolischen Gesellschaftsvertrag“ oder auch „kulturellen Kompromiss“, wie Wimmer es nennt. Die Kompromissformeln hätten häufig deshalb symbolischen Charakter, weil die semantische Überdichte und mehrseitige Anschlussfähigkeit von Symbolen es erlaube, sich aus unterschiedlichen Interessenslagen heraus darauf zu verständigen. Ein kultureller Kompromiss stelle sich ein, wenn alle in einer Arena aufeinander bezogenen Akteure ihre langfristigen Interessen in einer gemeinsamen Symbolik formulieren könnten. Kulturelle Kompromisse schließlich definierten dann auch die Grenzen zwischen denjenigen, die sich an ihnen beteiligen, und jenen, welche außerhalb ihres Geltungsbereiches stünden. Kulturelle Kompromissbildung sei also mit sozialer Schließung verbunden: „Wenn diese Distinktionspraxis zum Kernelement eines Wir-Gefühls einer Gruppe wird und sie sich als historische Abstammungsgemeinschaft versteht, also als Menschen gleicher Kultur und Herkunft, sprechen wir [...] von Ethnien“ (1996: 413). Die Ethnizitätsproblematik versteht Wimmer also - ganz im Sinne der gängigen konstruktivistischen Ethnizitätstheorien (vgl. Lentz 1995) - als Phänomen sozialer Abschließung, nicht als Ausdruck „objektiver“" kultureller Differenz.

Der Vorzug dieses Ansatzes ist zweifelsohne, dass er die Probleme der inneren Variabilität und der Machtgebundenheit von Kultur sowie des kulturellen Wandels zu thematisieren erlaubt. Er ermöglicht auch, die Kulturdiskurse und Abgrenzungsstrategien der Akteure selbst zu thematisieren, ohne ihren Essentialisierungen zu folgen oder sich in den Aporien einer statistischen Clusteranalyse zu verstricken. Kulturen sind hier jedenfalls nicht als Untersuchungseinheiten vorausgesetzt. Doch die „Aushandlungs“-Metapher unterstellt eine ausgeprägte Verbalisierungsfähigkeit und Strategiegeleitetheit gesellschaftlicher Gruppen. Das scheint der Bedeutung nicht-verbalisierter Routinen, die der Bourdieusche Habitus-Begriff impliziert, zu widersprechen. Überhaupt passt Wimmers „rational choice“-Verständnis von Handlungen und Akteuren nicht so recht zu dem eher kollektiv verankerten Konzept „kultureller Kompromisse“. Offen bleibt auch, wie das theoretische Programm für eine empirische Forschung zu operationalisieren wäre. ${ }^{24}$ Letztlich steht „Kultur“ auch bei Wimmer als Kurzformel für ein ganzes Bündel unterschiedlicher Phänomene, als begrifflicher „Joker“, der je nach Kontext sehr verschiedenartige Bedeutungen annehmen kann. Allerdings tragen seine Überlegungen nachhaltig zur notwendigen „Resoziologisierung“ des Kulturbegriffs bei und thematisieren explizit die problematischen Beziehungen zwischen machtförmigen Prozessen sozialer Gruppenbildung und kulturellen Distinktionspraktiken.

\section{Ausblick}

Gegen die inflationäre Verwendung des Kulturbegriffs außerhalb der Ethnologie - insbesondere auch in politisch-normativer Absicht in den Multikulturalismusdiskussionen - könnte man nichts unternehmen, resümiert Trouillot resigniert am Ende seiner kritischen Begriffsgeschichte. Er fordert, dass wenigstens die Ethnologen selbst den Kulturbegriff als analytisches Konzept aus ihren Arbeiten verbannen sollten. Ethnologen sollten stattdessen präziser benennen, worum es ihnen jeweils eigentlich geht: Ideologien, Normen und Werte, religiöse Glaubensvorstellungen, spezifische Praktiken, Rituale oder was auch immer:

„, The less culture is allowed to be a shortcut for too many things, the more sociocultural anthropology can thrive within its chosen domain of excellence, documenting how human thought is patterned and how those patterns are produced, rejected or acquired. Without culture, we will continue to need ethnography" (Trouillot 2002: 58).

24 Wimmers eigene Umsetzung des Programms (2005) in einigen Fallstudien, die vom Wandel indianischer Dorfgemeinden in Mexiko über die Globalisierung in einer kurdischen Siedlung im Irak bis hin zur Einwanderungspolitik der Schweiz reichen, überzeugt mich nicht vollständig - aber das näher auszuführen würde den Rahmen dieses Artikels sprengen. 
Ähnlich argumentieren auch Roger Keesing (1994), Adam Kuper (1999: 245ff), Chris Hann (2007) und andere Ethnologen und plädieren für einen Verzicht auf den Kulturbegriff. Bei einigen Soziologen zeichnet eine gegenläufige Entwicklung ab, wenn man Andreas Reckwitz' (2008) Plädoyer für einen geertzianisch fundierten umfassenden bedeutungsorientierten Kulturbegriff und eine Gemeinschaft und Kultur entkoppelnde „Kontingenzperspektive“ folgt. Aus Sicht der kulturskeptischen Ethnologen birgt diese Fokussierung auf die „symbolische Konstituiertheit [aller] menschlicher Handlungsformen“ (2008: 38) die Gefahr, Symbolsysteme als autonome Gebilde von historisch spezifischen, politischen Prozessen der Machtbildung abzukoppeln. Zugespitzt formuliert - und aus den jeweiligen Fachgeschichten verständlich - befürwortet Reckwitz eine „Kulturalisierung“ der Gesellschaftsanalyse, während die skeptischen Ethnologen eine „Soziologisierung“ der Kulturanalyse fordern bzw. „Kultur“ in konkrete untersuchbare Teilphänomene auflösen wollen.

Notwendig scheint mir, den Dialog weiterzuführen - über die Geertz-Rezeption und GeertzKritik hinaus. Drei Aspekte sind dabei für die Entwicklung gemeinsamer empirisch umsetzbarer Forschungsfragen besonders klärungsbedürftig. 1. Was ist das „Kulturelle“ - sollte es tatsächlich bedeutungstheoretisch gefasst werden - und wie unterscheidet es sich von anderen Aspekten menschlichen Handelns, oder wäre von differenzierungstheoretischen Ansätzen doch zu lernen? Sollten wir die heterogenen Bündel von Ideologien und Diskursen, verkörperlichten Praktiken, Ritualen und Symbolen nicht doch aufschnüren, statt sie alle unter dem Adjektiv „kulturelle“ Dimensionen zu fassen? 2. Welche Analyseeinheiten sollten wir abstecken, wenn wir sowohl „Kulturen“ als auch „Gesellschaften“ als essentialisierende Konzepte kritisieren? Ein Ergebnis der bisherigen Diskussion ist sicher, dass wir weder von nationalstaatlich verfassten „Gesellschaften“ (oder auch der „Weltgesellschaft“) noch von „Kulturen“ als Untersuchungseinheiten ausgehen können, weil kulturellen Praktiken keine homogenen Sets abgeben, die an bestimmte soziale Gruppen fest gebunden wären. Reckwitz' Anregung (2003: 295), die soziale Welt als ein Ensemble zu verstehen von ,lose gekoppelte[n] Komplexe[n] von Praktiken, die häufig nur bedingt und widerspruchsvoll aufeinander abgestimmt oder gegeneinander abgegrenzt sind“, und dabei „soziale Felder“ und „Lebensformen“ nicht von vornherein eng zu führen, scheint mir hier durchaus weiterführend. Doch in welchen Untersuchungseinheiten wären die Beziehungen zwischen kulturellen Codes und sozialen Gruppen erforschbar, wie lassen sich Mikro- und Makroebenen hier in den Blick nehmen, ohne Kulturelles wieder zu autonomisieren und Machtprozesse zu vernachlässigen? 3. Wie können wir die strategische Essentialisierungen von „Kultur“ untersuchen, die überall in der politischen Realität stattfinden, wo „Kultur“ zum Kampfbegriff wird und in die Sprache der gesellschaftlichen Akteure eingeht. Ein verstärkter Austausch zwischen Ethnologie und Soziologie über diese Fragen könnte für beide Disziplinen „Kultur“ als sinnvollen Fragehorizont rehabilitieren und vielleicht doch als „Brückenbegriff“ fruchtbar machen.

\section{Literatur}

Abu-Lughod, Lila (1991: Writing against culture, in: Fox, Richard. G. (Hrsg.), Recapturing Anthropology: Working in the Present, Santa Fe, S. 137-162.

Amann, Klaus / Stefan Hirschauer (1997): Die Befremdung der eigenen Kultur. Ein Programm, in: Stefan Hirschauer / Klaus Amann (Hrsg.), Die Befremdung der eigenen Kultur. Zur ethnographischen Herausforderung soziologischer Empirie, Frankfurt / Main, S. 7-52.

Arnold, Matthew (1882 [1869]): Culture and Anarchy, New York.

Bachmann-Medick, Doris (2006): Cultural Turns. Neuorientierungen in den Kulturwissenschaften, Reinbek / Hamburg.

Beck, Ulrich (2004): Der kosmopolitische Blick oder: Krieg ist Frieden, Frankfurt / Main. 
Benedict, Ruth (1932): Configurations of culture in North America, in: American Anthropologist 34, S. 1-27.

Benedict, Ruth (1989 [1934]): Patterns of Culture, Boston.

Benedict, Ruth (1946): The Chrysanthemum and the Sword: Patterns of Japanese Culture, Boston.

Boas, Franz (1938 [1911]): The Mind of Primitive Man, New York.

Brumann, Christoph (1999): Writing for culture: why a successful concept should not be discarded, in: Current Anthropology 40, Supplement, S. 1-27.

Boonzaier, Emile (1988): „Race“ and the race paradigm, in: Ders. / John Sharp (Hrsg.), South African Keywords: The Uses and Abuses of Political Concepts, Cape Town, S. 58-67.

Çaglar, Ayșe (1990): The prison house of culture in the study of Turks in Germany, in: Sozialanthropologische Arbeitspapiere 31, Institut für Ethnologie, Freie Universität Berlin.

Clifford, James (1988): On ethnographic authority, in: Ders., The Predicament of Culture: Twentieth Century Ethnography, Literature, and Art, Cambridge, S. 21-54.

Clifford, James / George E. Marcus (Hrsg.) (1986): Writing Culture: The Poetics and Politics of Ethnography, Berkeley.

Crapanzano, Vincent (1986): Hermes' dilemma: the masking of subversion in ethnographic description, in: James Clifford/ George E. Marcus (Hrsg.), Writing Culture: The Poetics and Politics of Ethnography, Berkeley, S. 51-76.

Dürr, Michael / Erich Kasten / Egon Renner (Hrsg.) (1992): Franz Boas. Ethnologe - Anthropologe Sprachwissenschaftler. Ein Wegbereiter der modernen Wissenschaft vom Menschen, Berlin: Staatsbibliothek zu Berlin / Preußischer Kulturbesitz.

Eriksen, Thomas Hylland / Finn Sievert Nielsen (2001): A History of Anthropology, London.

Geertz, Clifford (1973): After the revolution: the fate of nationalism in the new states, in: Ders., The Interpretation of Cultures, New York, S. 234-254.

Geertz, Clifford (1987): Dichte Beschreibung. Beiträge zum Verstehen kultureller Systeme, Frankfurt / Main.

Geertz, Clifford (1995): After the Fact: Two Countries, Four Decades, One Anthropologist, Cambridge.

Goody, Jack (1994): Culture and its boundaries, in: Borofsky, Robert (Hrsg.), Assessing Cultural Anthropology, New York, S. 250-261.

Gottowik, Volker (1997): Konstruktionen des Anderen. Clifford Geertz und die Krise der ethnographischen Repräsentation, Berlin.

Hall, Stuart (2004): Die Frage des Multikulturalismus, in: Ders., Ideologie - Identität - Repräsentation. Ausgewählte Schriften 4, Hamburg, S. 188-227.

Hann, Chris (2007): Weder nach dem Revolver noch nach dem Scheckbuch, sondern nach dem Rotstift greifen: Plädoyer eines Ethnologen für die Abschaffung des Kulturbegriffs (mit Repliken von Rolf Lindner, Doris Bachmann-Medick, Aleida Assmann, Albrecht Kokorschke), in: Zeitschrift für Kulturwissenschaften 1, S. 125-146.

Hauck, Gerhard (2006): Kultur. Zur Karriere eines sozialwissenschaftlichen Begriffs, Münster.

Hirschauer, Stefan (2008): Die Empiriegeladenheit von Theorien und der Erfindungsreichtum der Praxis, in: Herbert Kalthoff et al. (Hrsg.): Theoretische Empirie. Zur Relevanz qualitativer Forschung, Frankfurt / Main.

Hörning, Karl H. (2008): Schwieriges Verhältnis. Schwellen zwischen Ethnologie und Soziologie, in: Paideuma 54, S. 41-58.

Hörning, Karl H. / Julia Reuter (Hrsg.) (2004): Doing Culture. Neue Positionen zum Verhältnis von Kultur und sozialer Praxis, Bielefeld.

Huntington, Samuel (1993): The clash of civilizations?, in: Foreign Affairs 72 / 3, S. 22-49. 
Kaschuba, Wolfgang (1995): Vom Verschwinden des Sozialen im gesellschaftlichen Diskurs, in: Zeitschrift für Volkskunde 91, S. 27-46.

Keesing, Roger M. (1987): Anthropology as interpretive quest, in: Current Anthropology 28, S. 161-176.

Keesing, Roger M. (1994): Theories of culture revisited, in: Robert Borofsky (Hrsg.), Assessin Cultural Anthropology, New York, S. 301-312.

Kohl, Karl-Heinz (1993): Ethnologie - die Wissenschaft vom kulturell Fremden. Eine Einführung, München.

Kroeber, Alfred L. (1917): The superorganic, in: American Anthropologist 19, S. 163-213.

Kroeber, Alfred L. / Talcott Parsons (1958): The concept of culture and of social system, in: American Sociological Review 23 / 5, S. 582-583.

Kroeber, Alfred L. / Clyde Kluckhohn (1952): Culture: A Critical Review of Concepts and Definitions, New York.

Kuper, Adam (1999): Culture: The Anthropologist's Account, Cambridge.

Kuper, Adam (2006): The culture of discrimination, in: Reginald Byron / Ullrich Kockel (Hrsg.), Negotiating Culture: Moving, Mixing and Memory in Contemporary Europe, Berlin, S. 186-200.

Layton, Robert (1997): An Introduction to Theory in Anthropology, Cambridge.

Lentz, Carola (1995): „Tribalismus“ und Ethnizität in Afrika - ein Forschungsüberblick, in: Leviathan 23, S. 115-145.

Lentz, Carola (2001): Kultur, in: Jacob E. Mabe (Hrsg.), Das Afrika-Lexikon, Wuppertal, S. 323-325.

Maderthaner, Wolfgang / Lutz Musner (2007): Die Selbstabschaffung der Vernunft. Die Sozialwissenschaften und die Krise des Sozialen, Wien.

Medick, Hans (1992): Plebejische Kultur, plebejische Öffentlichkeit, plebejische Ökonomie. Über die Erfahrungen und Verhaltensweisen Besitzarmer und Besitzloser in der Übergangsphase zum Kapitalismus, in: Robert Berdahl et al. (Hrsg.), Klassen und Kultur. Sozialanthropologische Perspektiven in der Geschichtsschreibung, Frankfurt / Main, S. 157-204.

Medick, Hans (1984): „Missionare im Ruderboot“”? Ethnologische Erkenntnisweisen als Herausforderung an die Sozialgeschichte, in: Geschichte und Gesellschaft 10 / 3, S. 295-319.

Moebius, Stephan / Dirk Quadflieg (Hrsg.) (2006): Kultur. Theorien der Gegenwart, Wiesbaden.

Petermann, Werner (2004): Die Geschichte der Ethnologie, Wuppertal.

Ortner, Sherry (1999): Introduction, in: Dies. (Hrsg.), The Fate of „Culture“: Geertz and Beyond, Berkeley, S. 1-13.

Parsons, Talcott (1951): The Social System, New York.

Radcliffe-Brown, A. R. (1952): Structure and Function in Primitive Society, London.

Reckwitz, Andreas (2003): Grundelemente einer Theorie sozialer Praktiken. Eine sozialtheoretische Perspektive, in: Zeitschrift für Soziologie 32 / 4, S. 282-301.

Reckwitz, Andreas (2006 [2000]): Die Transformation der Kulturtheorien. Zur Entwicklung eines Theorieprogramms, Weilerswist.

Reckwitz, Andreas (2008): Unscharfe Grenzen. Perspektiven der Kultursoziologie, Bielefeld.

Sangren, Steven (1988): Rhetoric and the authority of ethnography: „postmodernism“ and the social reproduction of texts, in: Current Anthropology 29/3, S. 405-435.

Sapir, Edward (1917): Do we need a „superorganic“?, in: American Anthropologist 19, S. 441-447.

Sapir, Edward (1924): Culture, genuine and spurious, in: American Journal of Sociology 29 / 4, S. 401-429.

Schiffauer, Werner (1999): Kultur als Diskursfeld, in: Frankfurter Rundschau vom 27.4.1999. 
Stocking, George W. (1974): The basic assumptions of Boasian anthropology, in: Ders. (Hrsg.), The Shaping of American Anthropology, 1883-1911: A Franz Boas Reader, Chicago, S. 1-20.

Stocking, George W. (1986): Essays on culture and personality, in: Ders. (Hrsg.), Malinowski, Rivers, Benedict and Others: Essays on Culture and Personality, Madison, S. 3-12.

Stolcke, Verena (1995): Talking culture: new boundaries, new rhetorics of exclusion in Europe, in: Current Anthropology 36/1, S. 1-24.

Taylor, Charles (1997): Multikulturalismus und die Politik der Anerkennung (hrsg. von Amy Gutmann). Frankfurt / Main.

Thornton, Robert (1988): Culture: a contemporary definition, in: Emile Boozaier / John Sharp (Hrsg.), South African Keywords: The Uses and Abuses of Political Concepts, Cape Town, S. 17-28.

Trouillot, Michel-Rolph (1991): Anthropology and the savage slot: the poetics and politics of otherness, in: Richard. G. Fox (Hrsg.), Recapturing Anthropology: Working in the Present, Santa Fe, S. 17-44.

Trouillot, Michel-Rolph (2002): Adieu, culture: a new duty arises, in: Richard G. Fox / Barbara J. King (Hrsg.), Anthropology Beyond Culture, Oxford, S. 37-60.

Tylor, Edward Burnett (1920 [1871]): Primitive Culture, New York.

Wimmer, Andreas (1996): Kultur. Zur Reformulierung eines ethnologischen Grundbegriffs, in: Kölner Zeitschrift für Soziologie und Sozialpsychologie 48, S. 401-425.

Wimmer, Andreas (2005): Kultur als Prozess. Zur Dynamik des Aushandelns von Bedeutungen, Wiesbaden.

Wolf, Eric (1982): Europe and the People without History, Berkeley.

Zitelmann, Thomas (2001): Kulturkreise, in: Jacob E. Mabe (Hrsg.), Das Afrika-Lexikon, Wuppertal, S. 325-326.

Prof. Dr. Carola Lentz Johannes Gutenberg-Universität Mainz Institut für Ethnologie und Afrikastudien Forum universitatis 6 55099 Mainz lentz@uni-mainz.de 